\title{
Patient Satisfaction with Family Physician Colonoscopists
}

\author{
CPT Upneet K. Nijiar, MD, LTC, John A. Edwards, MD, MPH, \\ and MAJ Matthew W. Short, MD
}

Purpose: Assessing patient satisfaction after endoscopy with a standardized survey is recommended by gastrointestinal professional societies. The purpose of this study was to assess both patient satisfaction with colonoscopy performed by family physicians and physicians' technical competence in colonoscopy.

Methods: Modified Group Health Association of America 9 surveys were sent to all 230 patients who received a colonoscopy by family physicians at Madigan Army Medical Center from June to December 2007. Responses were graded on a 5-point Likert scale (LS), with a score of $\geq 3$ (good to excellent) defined as a favorable response. Procedure reports and medical records were reviewed for all patients, and selected quality indicators were compared with recommended colonoscopy standards.

Results: Sixty-nine percent of patients responded: 85 men (54\%; mean age \pm SD, $54.9 \pm 5.6$ years) and 73 women $(46 \%$; mean age \pm SD, $54.3 \pm 4.3$ years). The overall rating of the visit received a favorable response rate of $98 \%$ (average $\mathrm{LS}$ rating, 4.6). Nearly all patients said they would have the procedure repeated by the same physician $(98 \%)$ and at the same facility $(98 \%)$. The overall reach-the-cecum rate was $100 \%$. Adenomas were detected in $22 \%$ of women and $36 \%$ of men. All polyps measuring $<2$ $\mathrm{cm}$ were removed, and $99 \%$ of the procedures had scope withdrawal times of at least 6 minutes. Hemostasis techniques were used for 2 patients after polypectomy. There were no perforations.

Conclusion: Family physicians can perform colonoscopy with a high level of accuracy, safety, and patient satisfaction. (J Am Board Fam Med 2011;24:51-56.)

Keywords: Colonoscopy, Colorectal Cancer Screening, Patient Satisfaction, Quality of Care

Screening for colorectal cancer is recommended beginning at age $50,{ }^{1}$ with colonoscopy being the preferred prevention strategy recommended by the American College of Gastroenterology. ${ }^{2}$ There has been a substantial demand for colonoscopy based on these recommendations and a growing population over age $50 .^{3}$ Family physicians have con-

This article was externally peer reviewed.

Submitted 6 May 2010; revised 1 September 2010; accepted 4 October 2010.

From the Department of Family Medicine, Madigan Army Medical Center, Tacoma, WA.

Funding: none.

Prior Presentation: Poster presentation at the National Uniformed Services Academy of Family Physicians Annual Meeting; April 3-8, 2009; Orlando, FL.

Conflict of interest: none declared.

Disclaimer: The views expressed are those of the authors and do not reflect the official policy of the Department of the Army, the Department of Defense, or the U.S. Government.

Corresponding author: Maj. Matthew W. Short, MD, Madigan Army Medical Center, 9040 Jackson Ave., Tacoma, WA 98431 (E-mail: matthew.w.short@us.army.mil). tributed to meeting this demand by providing colonoscopy services. $^{4-11}$

The American Society for Gastrointestinal Endoscopy (ASGE) and the American College of Gastroenterology (ACG) have recently established practical quality measures to grade endoscopy performance. ${ }^{12-14}$ Assessing patient satisfaction with gastrointestinal endoscopic procedures is one of the postprocedure indicators recommended by the ASGE and ACG to evaluate the quality of outcomes. ${ }^{14,15}$ The use of a modified Group Health Association of America (GHAA) 9 patient satisfaction survey has been recommended because it has been validated in numerous patient populations and has been in existence for more than 20 years. ${ }^{16}$ Despite the availability and common use of this patient satisfaction survey, little published data exists about colonoscopy performed by gastroenterologists, ${ }^{17}$ and no data exists about colonoscopy performed by primary care physicians. 
One of the questions in the GHAA 9 survey asks patients to assess the technical skills of their physician. This question has been difficult to validate because patients do not feel qualified to answer the question. ${ }^{17}$ Additional quality indicators have been recommended by the ASGE and ACG to evaluate technical colonoscopy skills. ${ }^{13}$ The purpose of this study was to assess both patient satisfaction with colonoscopy performed by family physicians using a modified GHAA 9 questionnaire and family physician technical competence in colonoscopy using recommended quality indicators.

\section{Methods}

\section{Patient Satisfaction}

A modified GHAA 9 patient satisfaction survey and a short letter stating its purpose were sent to 230 consecutive patients who received a colonoscopy by family physician endoscopists at Madigan Army Medical Center from June to December 2007. The survey included 12 questions that inquired about the patients' colonoscopy experience (Figure 1). Nine of the questions were from a previously validated GHAA 9 colonoscopy survey. ${ }^{17}$ Three additional questions inquired about the quality of the group education visit, the level of pain control, and whether this was their first colonoscopy. A single follow-up survey was sent to nonresponders to increase the response rate.

Nine survey questions used a 5-point Likert scale (LS) to grade responses $(1=$ poor, 2 = fair, $3=\operatorname{good}, 4=$ very good, $5=$ excellent). A score of $\geq 3$ was considered a favorable response. The favorable response rate (FRR) for each question was calculated using the total number of favorable responses divided by the total number of responses for that question, which was validated in a previous gastroenterology study. ${ }^{17}$ Three additional survey questions were answered as yes or no.

\section{Technical Skills of the Family Physicians}

Both family physicians in this study possessed the skills to perform complete colonoscopy, including snare polypectomy and management of bleeds after polypectomy using thermal and nonthermal modalities. The technical skills of the physicians in this study were assessed by reviewing all 230 procedure reports, measuring 6 key colonoscopy quality indicators, and comparing those with recommended competency standards as put forth by the ASGE and ACG. Additional patient demographic data were also obtained through chart review.

\section{Quality Indicators for Colonoscopy}

Reach-the-Cecum Rate

All procedure reports were reviewed for written documentation and photographic evidence of cecal landmarks to determine if the cecum had been intubated in each procedure. Quality endoscopists are expected to reach the cecum in $95 \%$ of procedures performed. ${ }^{13}$

\section{Adenoma Detection Rate}

Pathology reports for all patients who received a screening colonoscopy after the age of 50 were

Figure 1. Colonoscopy Satisfaction Questionnaire. *Questions were not included in Group Health Association of America 9 survey.

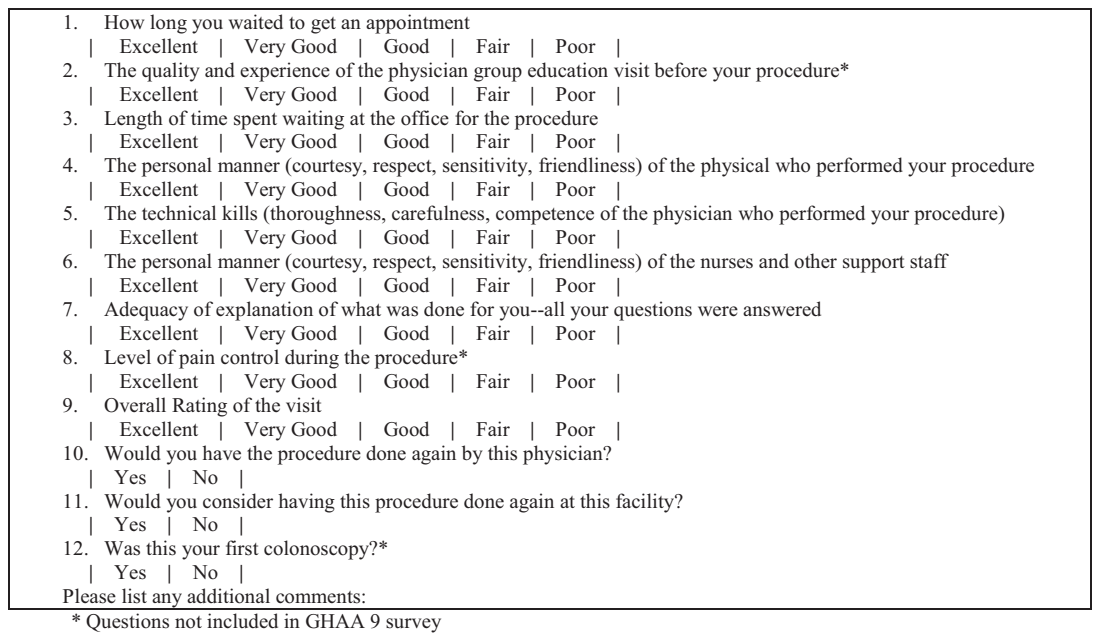


reviewed. The detection rate for adenomas and other dysplastic polyps was determined. Dysplastic polyps were defined as tubular adenomas, serrated adenomas, tubulovillous adenomas, villous adenomas, high-grade dysplasias, or adenocarcinomas. Among asymptomatic individuals undergoing a screening colonoscopy after the age of 50, the expected adenoma detection rate is $15 \%$ for women and $25 \%$ for men. ${ }^{13}$

\section{Polyp Resection Attempt}

The endoscopic findings and physician recommendations from all procedure reports were reviewed. The number of mucosally based polyps measuring $<2 \mathrm{~cm}$ that were endoscopically removed and not sent for surgical resection was determined. It is expected that a quality endoscopist will attempt the endoscopic resection of all mucosally based polyps measuring $<2 \mathrm{~cm}$ before referring a patient for surgical resection. ${ }^{13}$

\section{Withdrawal Times}

All sedation nursing records were reviewed to determine the withdrawal time from the cecum until scope removal. Longer withdrawal times have demonstrated increased detection of significant neoplastic lesions during colonoscopic examinations. Mean withdrawal time should be at least 6 minutes. $^{13}$

\section{Bleeding Rate}

All procedure reports were reviewed for immediate bleeding complications. The patients' electronic medical records were also reviewed for at least 6 months after the procedure to look for delayed bleeding complications that required a repeat colonoscopy or hospital admission. The bleeding complication rate should be $<1 \% .^{13}$

\section{Perforation Rate}

All procedure reports were reviewed for immediate perforations at the time of endoscopy. Patients' electronic medical records were also reviewed for at least 6 months after the procedure to look for any colon perforations that were diagnosed after endoscopy. The perforation rate should be $<0.1 \% .{ }^{13}$

\section{Data Analysis}

The survey data were consolidated into an Excel spreadsheet (Microsoft Corporation, Redmond, WA) and statistical analysis was performed using
SPSS software, version 14 (SPSS Science Inc., Chicago, IL). Mann-Whitney $U$ and $\chi^{2}$ tests were used to compare the statistical differences between respondents and nonrespondents. There were no exclusion criteria. The population used in this study was based on a convenience sample without exclusion criteria, so a prospective power analysis was not performed. Descriptive statistics were used for physician technical skills and quality indicators.

This study received institutional review board approval from Madigan Army Medical Center, Fort Lewis, WA. Survey mailings were funded by the Department of Family Medicine.

\section{Results}

Surveys were sent to 230 patients who received a colonoscopy by a family physician during the 6-month period; 158 surveys were returned (69\%). Respondents included 85 men (54\%; mean age \pm SD, $54.9 \pm 5.6$ years) and 73 women (46\%; mean age $\pm \mathrm{SD}, 54.3 \pm 4.3$ years). Two patients did not receive the survey because of incorrect addresses confirmed by return of the mailed packet, and they were included in the nonresponder group. This was the first colonoscopy experience for $86 \%$ of respondents. The most common indication for the procedure was average-risk colorectal cancer screening (Table 1).

\section{Patient Satisfaction}

The question inquiring about the overall rating of the procedure visit received a FRR of 98\% (LS rating, 4.6), with most patients saying they would have the procedure repeated by the same physician (98\%) and at the same facility (98\%). There was a high FRR for all survey questions (Table 2). There was no statistically significant difference between

Table 1. Indications for Colonoscopy

\begin{tabular}{lc}
\hline Procedure Indications $^{*}$ & Total $(\mathrm{n}=230)$ \\
\hline Average risk screening & $180(78.3)$ \\
Family history of polyps & $27(11.7)$ \\
Family history of colon cancer & $21(9.1)$ \\
Personal history of polyps & $8(3.5)$ \\
Hematochezia & $7(3.0)$ \\
Abdominal pain & $2(0.9)$ \\
Chronic diarrhea & $1(0.4)$ \\
\hline
\end{tabular}

Values presented as $\mathrm{n}(\%)$.

*Some patients had more than one procedure indication. 
Table 2. Survey Results

\begin{tabular}{lcc}
\hline Survey Questions & FRR (\%) & $\begin{array}{c}\text { Average Likert } \\
\text { Scale Rating }\end{array}$ \\
\hline Likert scale & & \\
$\quad$ Appointment wait time & 89.3 & 3.9 \\
$\quad$ Quality of the group & 99.4 & 4.6 \\
$\quad$ education visit* & & \\
Waiting on procedure day & 97.5 & 4.4 \\
Personal manner of physician & 98.7 & 4.6 \\
Technical skills of physician & 100.0 & 4.7 \\
Personal manner support & 99.4 & 4.7 \\
$\quad$ staff & & \\
Adequacy of explanation of & 100.0 & 4.7 \\
$\quad$ what was done & & 4.6 \\
Level of pain control* & 95.6 & 4.6 \\
Overall rating of visit & 97.5 & \\
Yes/No & & \\
Would have procedure by & $97.5 \%$ & \\
$\quad$ same physician & & \\
Would have procedure at & $97.5 \%$ & \\
$\quad$ same facility & & \\
First colonoscopy experience* & $86.2 \%$ & \\
\hline
\end{tabular}

*Questions not included in Group Health Association of America 9 survey.

FRR, favorable response rate.

respondents and nonrespondents based on sex, medication dosage, or procedure time (Table 3). Respondents were an average of 2.4 years older than nonrespondents $(P<.01)$.

\section{Technical Skills of the Family Physicians}

The family physicians in this study met or exceeded all recommended quality indicator standards. The reach-the-cecum rate was $100 \%$. Of the $230 \mathrm{pa}-$ tients, $210(91 \%)$ were older than 50 and were receiving a colonoscopy for asymptomatic colon cancer screening. Among those patients, adenomas
Table 4. Most Common Diagnoses

\begin{tabular}{lc}
\hline Diagnosis* & Cases (n) \\
\hline Tubular adenoma & 98 \\
Hyperplastic polyp & 83 \\
Lymphoid aggregate & 24 \\
Colitis & 5 \\
Inflammatory polyp & 4 \\
Serrated adenoma & 3
\end{tabular}

*Some patients had more than one pathology diagnosis.

were detected in $22 \%$ of the women (24 of 108$)$ and $36 \%$ of the men (37 of 102 ).

All polyps measuring $<2 \mathrm{~cm}(\mathrm{n}=226)$ were removed using both snare polypectomy $(\mathrm{n}=48)$ and cold biopsy polypectomy $(n=178)$. The most common pathology diagnoses were tubular adenomas and hyperplastic polyps (Table 4).

A record of the colonoscopy withdrawal time was documented in 219 of the 230 cases. Of those procedures, the average length of withdrawal was 13 minutes, with $99 \%$ of patients (217 of 219) having a withdrawal time of at least 6 minutes. The remaining 2 procedures had documented withdrawal times of 5 minutes.

Epinephrine and a hemostatic clip were each used once during the procedure for mild bleeding after polyectomy $(0.9 \%)$. At review of the medical records 6 months after the procedure date there were no perforations, delayed bleeding, or other significant complications in any of the procedures performed.

\section{Discussion}

This is the first study using the recommended GHAA 9 survey to inquire about patient satisfac-

Table 3. Comparison of Survey Participants

\begin{tabular}{|c|c|c|c|c|}
\hline Comparisons of Variables & Total & Respondents & Nonrespondents & $P$ \\
\hline \multicolumn{5}{|l|}{$\operatorname{Sex}(n[\%])$} \\
\hline Male & 117 & $85(54)$ & $32(44)$ & $.24^{*}$ \\
\hline Female & 113 & $73(46)$ & $40(56)$ & \\
\hline Age, yr (mean $[\mathrm{SD}]$ ) & $54.0(5.7)$ & $54.7(5.0)$ & $52.3(6.6)$ & $<.01^{\dagger}$ \\
\hline Fentanyl, $\mu \mathrm{g}$ (mean $[\mathrm{SD}]$ ) & $112.5(32.9)$ & $113.1(34.7)$ & $111.4(29.6)$ & $.38^{\dagger}$ \\
\hline Midazolam, mg (mean [\%]) & $4.6(1.3)$ & $4.7(1.4)$ & $4.4(1.1)$ & $.53^{\dagger}$ \\
\hline Procedure time, min (mean [\%]) & $0: 24(0: 12)$ & $0: 23(0: 10)$ & $0: 26(0: 15)$ & $.16^{\dagger}$ \\
\hline
\end{tabular}

${ }^{*} \chi^{2}$ test.

${ }^{\dagger}$ Mann-Whitney U test. 
tion with colonoscopy services provided by family physicians. The FRRs of family physicians performing advanced endoscopy in this study are very high. A vast majority of patients responded that they would have the procedure done by the same physician and at the same facility.

\section{Patient Satisfaction among Specialties}

There is only one study in the literature that used the GHAA 9 questionnaire to evaluate patient satisfaction with endoscopy performed by gastroenterologists. ${ }^{17}$ This 2007 study conducted in Spain randomly selected 642 patients to receive the survey by telephone interview, with 537 (84\%) of the patients completing the survey. Of the patients surveyed, approximately half received a colonoscopy and half received upper endoscopy. This study used 8 of the 9 GHAA 9 survey questions; it did not include the question pertaining to technical skills of the physician. Patient satisfaction with family physician endoscopists in our study is high and comparable to this previously published gastroenterology data (Table 5). Family physicians in our study had a higher FRR for the adequacy of the explanation given to the patient after the procedure (100\% vs $96 \%$ ), although differences in study methods and patient populations between the 2 studies prevent direct comparison.

\section{Family Physicians' Technical Skills}

The family physicians in our study provided safe and accurate colonoscopy as measured by established gastroenterology quality indicators. Reachthe-cecum and adenoma detection rates were very high, and there were no significant complications or hospitalizations as a result of the procedures.

Table 5. Comparison with Published Gastroenterology Data $^{17}$

\begin{tabular}{lcc}
\hline & \multicolumn{2}{c}{ FRR (\%) } \\
\cline { 2 - 3 } Survey Question & $\begin{array}{c}\text { Family } \\
\text { Medicine }\end{array}$ & Gastroenterology \\
\hline Level of pain control & 95.6 & 96.6 \\
Procedure explanation & 100 & 96.1 \\
Personal manner of physician & 98.7 & 98.3 \\
Personal manner of support & 99.4 & 99.4 \\
$\quad$ staff & & \\
Waiting on procedure day & 97.5 & 96.5 \\
Appointment wait time & 89.3 & 90.7 \\
\hline
\end{tabular}

FRR, favorable response rate.
Although patients may not be qualified to assess the technical skills of their physicians during a sedated procedure, the $100 \%$ FRR by patients of their physicians' technical skills does favorably compare with the physicians' technical performance based on published quality indicators. Our study continues to show that family physicians can provide quality endoscopy services.

\section{Quality Improvement}

Results from this survey can be used for quality improvement. In the comments section of the survey, some patients reported that the bowel preparation was the worst part of their colonoscopy experience. This cohort of patients received a 2-gallon bowel preparation with polyethylene glycol and electrolytes solutions. Since this study our facility has adopted a single-gallon split-dose bowel preparation, which has provided quality bowel cleansing and has been received well by patients.

Compared with other questions, FRRs for appointment wait times were lower in both our study and the previous gastroenterology study. This question reflects patient access to endoscopy procedures. Improving access to colonoscopy is a shared goal in endoscopy centers across the country given the supply and demand discrepancy growing in our health care system. ${ }^{3}$

This study also gives a unique look at patients' perceptions of family physician endoscopists based on their colonoscopy experience. These results continue to support that family physicians are meeting quality outcomes recommended by gastrointestinal societies. ${ }^{12-14}$ In today's emerging role of management systems, quality of care will become one of the leading means of recruiting patients. Patients are being viewed as consumers who may choose physician services or specific health care centers based primarily on quality reputations. ${ }^{12,16}$ Growing influence from accrediting organizations, employer coalitions, and patients have encouraged ongoing outcome assessment and accountability. Our study is also a reflection of the importance of physicians gathering data during their day-to-day practice and using these measures to make continual improvements to patient care. ${ }^{18,19}$

\section{Study Limitations}

Despite a good response rate, some nonresponse bias may exist. Some patients also completed their survey weeks after their procedure, which may have 
influenced survey results and response rates. An additional limitation is that questions regarding the group visit and level of pain control were not validated before their use in the survey.

\section{Conclusion}

Despite the limitations mentioned above, the major contributions of this study are showing that patient satisfaction with family physician endoscopists is very high and that family physicians can perform colonoscopy with a high level of accuracy and safety. Future studies should continue to compare family physician performance with established quality indicators to demonstrate endoscopy expertise.

\section{References}

1. U.S. Preventive Services Task Force. Screening for colorectal cancer: U.S. Preventive Services Task Force recommendation statement. Ann Intern Med 2008;149:627-37.

2. Dominic OG, McGarrity T, Dignan M, Lengerich EJ. American College of Gastroenterology Guidelines for Colorectal Cancer Screening 2008. Am J Gastroenterol 2009;104:2626-7.

3. Rex DK, Lieberman DA. Feasibility of colonoscopy screening: discussion of issues and recommendations regarding implementation. Gastrointest Endosc 2001;54:662-7.

4. Eckert LD, Short MW, Domagalski JE, Jaboori KA, Short PA. Assessing colonoscopy training outcomes using quality indicators. J Grad Med Educ 2009;1: 89-92.

5. Wilkins T, LeClair B, Smolkin M, et al. Screening colonoscopies by primary care physicians: a metaanalysis. Ann Fam Med 2009;7:56-62.

6. Short MW, Kelly KM, Runser LA. Colonoscopy by a family physician: a case series demonstrating health care savings. Mil Med 2007;172:1089-92.
7. Newman RJ, Nichols DB, Cummings DM. Outpatient colonoscopy by rural family physicians. Ann Fam Med 2005;3:122-5.

8. Kirby E. Colonoscopy procedures at a small rural hospital. Can J Rural Med 2004;9:89-93.

9. Edwards JK, Norris TE. Colonoscopy in rural communities: can family physicians perform the procedure with safe and efficacious results? J Am Board Fam Pract 2004;17:353-8.

10. Pierzchajlo RP, Ackermann RJ, Vogel RL. Colonoscopy performed by a family physician. A case series of 751 procedures. J Fam Pract 1997;44:473-80.

11. Hopper W, Kyker KA, Rodney WM. Colonoscopy by a family physician: a 9-year experience of 1048 procedures. J Fam Pract 1996;43:561-6.

12. Bjorkman DJ, Popp JW Jr. Measuring the quality of endoscopy. Gastrointest Endosc 2006;63(Suppl 4): S1-2.

13. Rex DK, Petrini JL, Baron TH, et al. Quality indicators for colonoscopy. Gastrointest Endosc 2006; 63(Suppl 4):S16-28.

14. Faigel DO, Pike IM, Baron TH, et al. Quality indicators for gastrointestinal endoscopic procedures: an introduction. Gastrointest Endosc 2006;63(Suppl 4): S3-9.

15. Quality improvement of gastrointestinal endoscopy: guidelines for clinical application. Form the ASGE. American Society for Gastrointestinal Endoscopy. Gastrointest Endosc 1999;49:842-4.

16. Johanson JF, Schmitt CM, Deas TM, et al. Quality and outcomes assessment in gastrointestinal endoscopy. Gastrointest Endosc 2000;52:827-30.

17. Del Río AS, Baudet JS, Fernández OA, Morales I, Socas Mdel R. Evaluation of patient satisfaction in gastrointestinal endoscopy. Eur J Gastroenterol Hepatol 2007;19:896-900.

18. Brown RD, Goldstein JL. Quality assurance in the endoscopy unit: an emphasis on outcomes. Gastrointest Endosc Clin N Am 1999;9:595-607.

19. Johanson JF. Importance of outcomes research in endoscopic practice. Gastrointest Endosc Clin N Am 1999;9:559-64. 